\title{
Effect of Haemorrhage upon the Rate of the Denervated Heart of Cats.
}

\author{
By \\ TAISUKE SUZUKI. \\ (砱 木 退 輔) \\ (From the Physiological Laboratory of Prof. I. Satalié, \\ Toloku Imperial Unicersity, Sendai.)
}

That haemorrhage elicits as a rule a noteworthy acceleration in the heart rate of manmals* is a fact observed by several investigators. ${ }^{1-8)} \quad A$ few writers ${ }^{(10)}$ however came across instances of haemorrhage producing a decrease of the heart frequency or failing to produce any increase thereof.

In general it is accepted nowadays, it may be recalled, that the net outcome of the effect of an agency affecting the heart rate is determined by the kind of animal, kind and depth of narcosis, handling of animal, etc. etc. Morphine which acts to increase the ragus tonus has been frequently employed in the experiments on dogs above referred to. Some writers as Dawson and Wiggers suggested the dependence of the amount of acceleration on the extent of the tonic activity of the vagus. The experiments on rabbits, of both investigators, ${ }^{9710)}$ who came to note only a retarding influence of the bleeding on the pulse rate, were carried out without narcosis. Bergendal used ether only during the operation and afterwards it was not given. If the rabbit is fastened on the table, the pulse rate is already remarkably accelerated, so that the effect of the ragotomy is no more perceptible than in the rabbit freely sitting without fastening or narcotizing. ${ }^{11}$ )

* The references have been limited in the present paper to the data on mammals.

1) E. J. Marey, Physiologie médicale de la circulation du sang, Paris 1863, $210 \mathrm{ff}$. (horse). 2) J. Bernstein, Ctrlbl. f. med. Wiss, 1867, 5. Year, 3 (dog; morphine). 3) G. II a y em, Arch. de Physiol. norm. et path., 188s, 4 Series 1 Part, 107 (cat). 4) P. M. Dawson, Am. J. Physiol., 1900(-01), 4, 6; J. Exp. Med., 1905, 7, 5 f. (dog; morphineether-chloroform). 5) C. J. Wiggers, Arch. of Int. Med., 1914, 14, 39 (animals with body weight of 6.1 to 17.0 kilos). 6) W. J. Meek and J. A. E. Eyster, Am. J. Physiol., 1921, 56, 4 (dog; morpbine). 7) Y. Doi, J. Physiol,, 1921, 55, 252 (cat, urethane). 8) A. Blalock and T. R. II arrison, Am. J. Physiol., 1927, 80, 157 (dog; morphine and one non-anaesthetized dog).

9) K. Bergendal, Skand. Arch. f. Physiol., 1897, 7, 186 (rabbit, ether during the operation only). 10) T. T'surumaki, Acta Schol. Med. Kyoto, 19(22-)23, 5, 464 f. (rabbit; no narcosis).

11) II. E. Iferring, Pflügers Arch., 1895, 60, $439 \mathrm{ff}$. 
Then in what manner is called forth the acceleration in the heart rate by the bleeding or the depression of the general blood pressure? In the hands of various investigators the one or both kinds of the extracardial nerves were divided with bleeding following, which yielded the results recapitnlated in the following paragraphs.

In the experiments of Bezol $d^{19}$ the bleeding occasioned a faster rate of the pulse when the vagus and cervical sympathetic nerves were divided, but the cervical cord remained intact, but when a certain level (25-30 mms. $\mathrm{Hg}$.) was reached in the blood pressure the pulse became slow. When all the heart nerves (the tissues between the aorta and pulmonary arteries including nerves and nerve cells) were beforehand singed off galvanocaustically, the bleeding evoked a reduction in the frequency of the heart contraction. In the experiments Bezold thought to find the testimony that the centre of the accelerating nerves in the cerebrum is excitable by the bleeding.

$\mathrm{Naw}$ row cki reported that the haemorrhage elicited no alteration in the pulse rate of the dog and cat when the vagus nerves were divided alone or together with the sympathetic nerves. ${ }^{13}$

In the experiments on the dog and rabbit poisoned with morphine and curara and placed under artificial respiration, Tschirje $w^{14)}$ mostly detected some acceleration in the frequency of the heart treated as below by the bleeding. In some cases the ragus, sympathetic and depressor nerves were bilaterally cut while in the other, besides the cervical nerves either the inferior cervical and stellate ganglia were removed or the cervical cord was sectioned above the atlas.

The slowing of the heart rate of rabbits of Bergendal, above related to, by blecding disappeared after the section of the vagi. MacWilliam is of opinion that the acceleration following the haemorrhage is due to the diminishing of the vagus control. ${ }^{15}$

Guthrie and Pike ${ }^{16)}$ produced great and rapid changes in blood pressure by occluding by means of a ligature and relcasing the thoracie aorta of

12) Bezold, Cited in $\mathrm{X}_{\text {a wrockit }}{ }^{14}$ p. $205 \mathrm{f}, \mathrm{T}$ schinjew ${ }^{5)}$ p. $118 \mathrm{f}$ and R.Tigerstedt Die Physiologie des Kreislaufes, II. Fd., II. Vol., 1921 Berlin and Leipzig, 441. N. B. In his book, III. Vol., 1928, 109 the work of Bernste in was cited as if the bleeding were done after the double ragotomy, but in fuct no record of such an experimentation was presented in the paper of Bernstein."

13) F. Nawrocki, Beitrige zur Anatomie und Physiologie als Festgabe Carl Ludwig, 1575 Leipzig, 205.

14) S. Tschirjew, Arch. f. Anat. u. Physiol, Physiol. Abt., 1877, 116.

15) J. A. M a cWilliam, Brit. Med. J., 1904, 789.

16) C. C. Guthrie and F. II. Pike, Am. J. Physiol., 1907, 18, 28. 
cats, and came to find that after complete section of the extrinsic cardiac nerves there is either no change in the pulse rate, or an increase in the rate with a fall in pressure and a decrease in rate with a rise in pressure.

The effect of stimulation of the peripheral end of the cervical cord or of the splanchnic nerve upon the rate of the heart denervated by interference of the ragi and accelerantes in the curarized dog of Johansson ${ }^{17}$ must be nowadays interpreted on the basis of the present state of our knowledge of the innervation of the secretion from the suprarenal gland and the liver as well.

While the investigations on the effect of the haemorrhage on the contraction rate of the denervated heart, the latests of which were carried out about two decades ago, yielded thus discordant results, our knowledge about the innervation of the heart, afferent as well as efferent, has been abundantly enriched, and a number of the factors which are capable of effecting the rate of the denervated heart has been recently discovered. Further a remarkable augmentation of the epinephrine secretion after the bleeding was definitcly established by Saito ${ }^{18)}$ While the experiments on the de-afferented dogs without narcotizing, fastening or laparotomy yielded a conspicuous augmentation of the epinephrine discharge, in the cava pocket experiments with etherized dogs he was not able to see a remarkable increase, but yet a definite, unmistakable acceleration was disclosed when one fifth of the total blood quantity was shed.

In following up these lines of thought, I have carried out bleeding of various mass on the urethanized cats, the vagus nerve and inferior cervical and stellata ganglia were bilaterally interfered with prior to the bleeding; the results will be presented briefly in the following pages.

Prior to the description of the present data some words will be spent of the effect of the pressure in the coronary circulation upon the beat rate of the isolated manumalian heart and that of the arterial as well as venous pressure on the denervated heart in situ in the animal body, all the remaining parts of which except the heart, lung and the lesser circulitory system are excluded from activity wholly or well nigh.

The experiments with the excised heart of mammals (cats, rabbits, dogs and guineapigs) of various investigators ${ }^{19}$ ) check with each other on the whole; the increase in pressure in the coronary arteries, up to a certain limit, causes increase in rate of beat, and the

17) J. E. Johansson, Arch. f. Anit. u. Physiol., Physiol. Abt., 1891, 110 f.

18) Shizu. Sa it o, Tohoku J. Exp. Med., 1928, 11, 79; also, Saito, Kamei and Tachi, Ibid., 1928, 11, 205 (The communication of W. Cram er, J. Physiol., 1918(-19), 52, xv, that severe haemorrhage produces an extensive depletion of the medullary cells, has been regrettably left out in the reference in the paper of T $\mathrm{T} \mathrm{ch}$ i from this laboratory, "Intluence of haemorrbage upon the epinephrine ( $\left.F_{0}+i n\right)$ content of suprarenals of the rabbit" (Tohoku J. Exp. Med., 1928, 18, 409)).).

19) G. B. Magrath and II. Kennedy, J. Exp. Med., 1897, 2, 13; A. IIerlitzka, Pflügers Arch., 1905, 107, 557 ; C. C. Guthrie and F. II. Pike, An. J. Physiol., 1907, $18,13$. 
fall in pressure a decrease in rate. In the experinents of $\mathrm{Magratb}$ and $\mathrm{K}$ enned $\mathrm{y}$ this inclination is noted.

Using the heart-lung preparation or similar method, several experimentalists ${ }^{10}$ were able to see the non-influence of changes within wide limits of arterial or venous pressure upon the frequency of the heart which is isolated from the rest of the body with the exception of the lungs, but conducting its function nearly as in the ordinary manner, that is sending the blood into the lesser, the coronary, and the artificial systemic circulatory route and receiving the blood returning therefrom. They altered, for instance, the arterial pressure within 30 and $150 \mathrm{mms}$. $\mathrm{Hg}$. (Martin), 58 and 147 (How ell and Donaldson) or 20 and 200 (K nowlton and Starling); but by such variation no change took place in the heart rate.

Methods:

Cats were used, and fed with a mixed diet (rice, fish and vegetables); but for two days before the experiment the food was not given.

The animal was narcotized by urethane given stomachically in a dose of 1 grm. per kilo of body weight. After the full development of the action of the drug, a matter of about one hour, it was fastened on the table provided with apparatus for electric heating.

Bilateral vagotomy in the neck and extirpation of the inferior cervical and stellate ganglia were done, and the left carotid artery prepared and connected with the Hüthle's spring manometer. 'The right carotid or femoral artery was prepared for bleeding.

Rectal temperature was measured from time to time. The blood volume of the cat was calculated at $5.5 \%$ of the body weight according to Meck and Gasser. ${ }^{2}$,

In connection with the preparation something may be again said of the denerrated heart as an indicator of the epinephrine secretion. $A$ history of this matter till 1921 is briefly given in a paper of $\mathrm{K}$ oda $\mathrm{ma}$ in 1923.92 ) We take this opportunity of correcting an erroneous reference on P. 174 in that paper. "it" in the phrase "Only, bilateral splanchnectomy was able to abolish it completely" should be qualified as the acceleration of the denervated heart due to sencory stimulation, but not by asphyxia. That a large increase in the rate of the denervated heart after the double splanchnicotomy is called forth by asphyxia had been noted eren by Cannon already at that time..$^{\prime \prime \prime}$

Of chemical agencies capable of affecting the denervated heart wbich originate from the animal tissues themselves and will be conveyed in the blood stream some new evidences were put forward recently. The secretion from the thyroid gland causes in acceleration of the denerrated heart; massage of the gland itself or stimulation of the cerrical sympathetic

20) II. N. Martin, Philosoph. Transac. Royal Soc. London, 185\%, 174, 67:; Wm. II. Iowell and F. Donaldson, Ibid, 1884, 175, $147 \mathrm{ff}$; II. E. ITering, Pflugers Arch., 1898, 72, 173; F. P. Knowlton and E. II. Starling, J. Physiol., 1912, 44, 206; Ch. Socin, Pflügers Arch., 1915, 160, 158.

21) W. J. Meek and II.S. Gasser, Am. J. Physiol, 1918, 47, :317.

22) Sakuji Kod am a, Tohoku J. Exp. Med., 1923, 4, $174 \mathrm{ff}$.

28) W. B. Cannon, $\Lambda$ m. J. Physiol., 1919, 50, 412. 
trunk increases the rate of the denerrated heart. Reflex secretion cccurs. ${ }^{24)}$ It is not necessary to take into consideration this agent in the present investigation, in which the inferior cervical and stellate ganglia were taken out. The stimulation of the liver nerves evoke also an acceleration of the denervated heart, ${ }^{25}$ and when sensory stimulation was applied after division of the liver nerres and removal of the suprarenals the denervated heart was found not accelerated or only a little accelerated.6) The effectiveness of stimulation of the hepatic nerves upon the denerrated heart is according to $\mathrm{Cannon}$ and his co-workers ${ }^{25} 2 \%$ ) dependent upon the feeding of the animals; the stimulation is most effective when meat or milk has been fed and the animal is digesting the meal. ${ }^{.7}$ ) The stimulation of the hepatic nerres was capable of accelerating only some 4 to 6 beats a minute in the animals which were fasting, while the same procedure caused the acceleration abore 20 or 30 beats in those which were digesting meat or meat and fat. ${ }^{-5}$ ) Those animals quoted in the paper of $\mathrm{Can}$ non in 1919,23$)$ which betrayed rery slight reflex effects on the denervated heart after

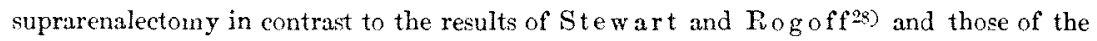
later investigation of Cannon himself, ${ }^{2(3)}$ were fasting for a day or two before the operation. .5 )

In the present investigations the animals were deprived of food, as above described, for two days before the experiment; accordingly the bepatic factor might play only a temporary and negligibly minor role in causing cardiac acceleration.

All the data abore referred to originate in the experiments under anaesthesia; the recent experiments of Cannon without narcosis gire eridently different results in some respects. ${ }^{-0)}$

\section{Results:}

In five cats one seventh of the total blood volume calculated according to Meek and $G$ asser was shed, in another five one fifth and in still another five one third. In cats 1,2 and 3 the blood was drawn from the femoral artery, but in the rest from the carotid.

With the cats in which one seventh of the total blood volume was bled, all the experiments were terminated artificially. The blood pressure fell clearly in response to bleeding, and in two cases it was remarkable, and in almost all cases the blood pressure did not reach the level recorded before bleeding till the termination of the experiment, that is the fall lasted at least from three to six hours. Only in Cat 1 the fall contimued not solong, and about two hours after blecling and the value taken before bleeding was recovered, but towards the end of the experiment the pressure set in again to decrease. The maximum of the fall was discovered in all the cases just at the end of the bleeding which occupied about one minute or a little longer or a few minutes later.

24) W. B. Cannon and P. E. Smith, Am. J. Physiol., 1922, 60, 476.

25) W. B. Cannon and J. E. Uridil, Ibid., 1921, 58, 353.

26) W. B. Cannon and D. Rapport, Ibid., 308.

27) W. B. Cann on and F. R. Griffith, Ibid., 1922, 60, 544.

28) G. N. Stew art and J. M. Rogoff, Ibid., 1920, 52, 304, \& 521.

29) W. B. Cannon, J. T. Lew is and S. W. Britton, Ibid., 1926, 77, 326. 


\begin{tabular}{|c|c|c|c|c|}
\hline \multirow{2}{*}{ 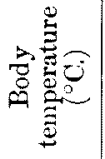 } & $\begin{array}{l}\text { quatuluadxa } \\
\text { Jo pug }\end{array}$ & 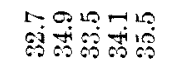 & 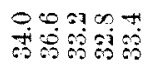 & 10300000 \\
\hline & $\begin{array}{l}\text { १uautuadxa } \\
\text { fo 8ิu!̣u!sag }\end{array}$ & $\begin{array}{l}0151=0 \\
00006050\end{array}$ & 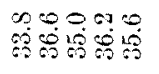 & $\begin{array}{l}01-01+61 \\
600000\end{array}$ \\
\hline \multirow{5}{*}{ 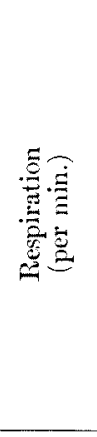 } & 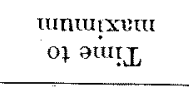 & 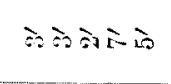 & 111 iि के & $\lim _{=}$ \\
\hline & 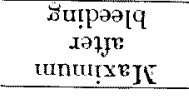 & 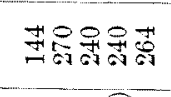 & $111 \frac{69}{696}$ & $\underset{7}{61}$ \\
\hline & $\begin{array}{l}\text { matumeu } \\
\text { of əut!J }\end{array}$ & 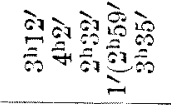 & $111 \stackrel{90}{3}=$ & 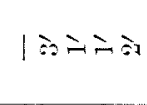 \\
\hline & 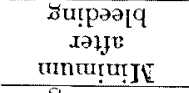 & $989 \frac{90}{63} 8$ & 111000 & 1 को \\
\hline & $\begin{array}{l}\text { 8utpəə[q } \\
\text { arogag }\end{array}$ & 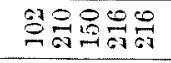 & $1 \mid 1000$ & $16 \underset{60}{60}$ \\
\hline \multirow{4}{*}{ 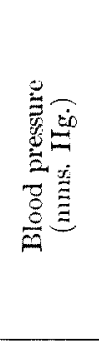 } & JipJ & 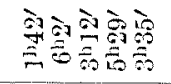 & 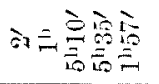 & 10 \\
\hline & $\begin{array}{l}\text { I[P] unuixtur } \\
\text { of amiL }\end{array}$ & I- & $00 \hat{D}_{0}^{10} \stackrel{10}{=}$ & खें के \\
\hline & $\begin{array}{c}\text { I[P] } \\
\text { cuntuixe]t }\end{array}$ & 6064080 & 10 $\frac{10}{9} 89$ & सी \\
\hline & $\begin{array}{l}\text { surparla } \\
\text { a.sofag }\end{array}$ & 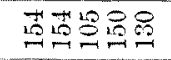 & 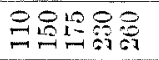 & $\begin{array}{l}60000 \\
=000\end{array}$ \\
\hline \multirow{4}{*}{ 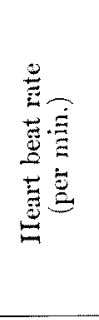 } & 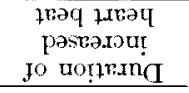 & 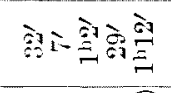 & छेస & 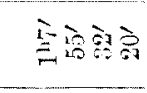 \\
\hline & 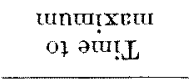 & ओने रे से & के चे चाने & बे = \\
\hline & $\begin{array}{l}\text { әsradout } \\
\text { mantugejt }\end{array}$ & 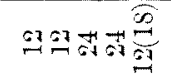 & 䑸 80 & $\infty \frac{0}{2} \frac{1}{50}$ \\
\hline & $\begin{array}{l}\text { surpoelq } \\
\text { ә.10زनd }\end{array}$ & कogeg & 00900 & 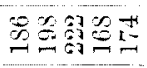 \\
\hline \multicolumn{2}{|c|}{ 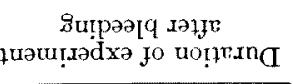 } & 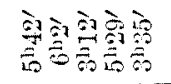 & 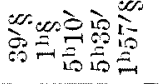 & 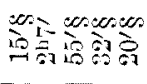 \\
\hline \multicolumn{2}{|c|}{ polq poolq jo әun $\Lambda$} & $\frac{1}{2}$ & 19 & $\frac{02}{n-1}$ \\
\hline \multicolumn{2}{|c|}{ 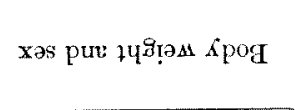 } & 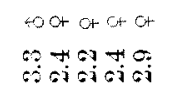 & 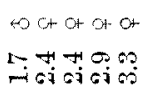 & 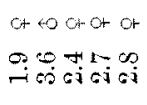 \\
\hline & $\begin{array}{l}(286 \mathrm{I}) \\
2 \mathcal{7}^{\mathrm{B}} \mathrm{C}\end{array}$ & 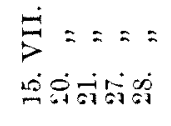 & 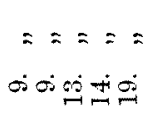 & $\begin{array}{l}=2=2= \\
6 j 6 j 69000 \\
676907\end{array}$ \\
\hline & कqun $N$ & -10300710 & $\cos -\infty=$ & $=0900$ \\
\hline
\end{tabular}




\section{Exampie I. \\ 21. VII. 1927. Cat $ণ 2.2$ kilos.}

9:0 2.2 grms. urethane stomachically. 9:40-10:30 Denervation of the heart, etc. 10:48-10:48:10" 17 c.c. blood (1/7 of total blood volume) were shed from femoral artery.

\begin{tabular}{|c|c|c|c|c|c|c|c|c|c|}
\hline \multirow[b]{2}{*}{ Time } & \multirow{2}{*}{\multicolumn{2}{|c|}{ Time after bleeding }} & \multicolumn{2}{|c|}{$\begin{array}{l}\text { Treart beat } \\
\text { (per min.) }\end{array}$} & \multicolumn{2}{|c|}{$\begin{array}{l}\text { Blood pressure } \\
\text { (mms. Hg.) }\end{array}$} & \multicolumn{2}{|c|}{$\begin{array}{c}\text { Respiration } \\
\text { (per min.) }\end{array}$} & \multirow{2}{*}{ 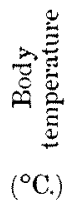 } \\
\hline & & & 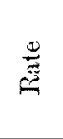 & 总 & $\frac{\vec{E}}{-\frac{\infty 0}{E}}$ & | & $\stackrel{\mathscr{E}}{\tilde{E}}$ & 莺 & \\
\hline $10: 40$ & \multirow{5}{*}{\multicolumn{2}{|c|}{$\begin{array}{l}\text { Begin of bleeding } \\
\text { End of bleeding } \\
\text { j' after bleeding }^{\prime}\end{array}$}} & 198 & & 105 & & 168 & & 35.5 \\
\hline $10: 47$ & & & 198 & & 105 & & 150 & & \\
\hline \multirow{7}{*}{$10: 48$} & & & 204 & +6 & 91 & -14 & & & \\
\hline & & & 216 & +18 & 70 & -35 & & & \\
\hline & & & 216 & +18 & 91 & -14 & 180 & +30 & \\
\hline & & $", \quad$, & 222 & +24 & 91 & -14 & 240 & +90 & \\
\hline & $3^{\prime}$ & $"$ & 210 & +12 & 91 & -14 & 228 & +78 & \\
\hline & $4^{\prime}$ & $"$ & 204 & +6 & 91 & -14 & 210 & +60 & \\
\hline & $5^{\prime}$ & $"$ & 210 & +12 & 91 & -14 & 192 & +42 & 35.3 \\
\hline $10: 55$ & $\bar{i}^{\prime}$ & $"$ & 216 & +18 & 84 & -21 & 168 & +18 & 35.2 \\
\hline 11:0 & $12^{\prime}$ & ” & 210 & +12 & 84 & -21 & 168 & +18 & 35.1 \\
\hline $11: 10$ & 22 & ", & 204 & +6 & 84 & -21 & 150 & 0 & 34.9 \\
\hline $11: 20$ & $32^{\prime}$ & $"$ & 204 & +6 & 84 & -21 & 120 & -30 & 34.8 \\
\hline $11: 30$ & $42^{\prime}$ & $"$ & 210 & +12 & 84 & -21 & 132 & -18 & 34.6 \\
\hline $11: 40$ & $52^{\prime}$ & $"$ & 204 & +6 & 84 & -21 & 132 & -18 & 34.5 \\
\hline 11.50 & lho' & $"$ & 204 & +6 & 84 & -21 & 120 & -30 & 34.4 \\
\hline 12:0 & $1^{h} 12^{\prime}$ & $"$ & 198 & 0 & 84 & -21 & 120 & -30 & 34.8 \\
\hline $12: 15$ & $1^{1,2} 7^{\prime}$ & 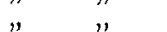 & 192 & -6 & 84 & -21 & 120 & -30 & 34.2 \\
\hline $12: 30$ & $1^{h} 42^{\prime}$ & , & 192 & -6 & 84 & -21 & 60 & -90 & 84.1 \\
\hline $12: 45$ & $1^{1}, 57^{\prime}$ & 3 & 192 & -6 & 84 & -21 & 72 & -78 & 34.0 \\
\hline $1: 0$ & $2^{11} 12^{\prime}$ & $"$ & 192 & -6 & 84 & -21 & 48 & -102 & 33.8 \\
\hline $1: 20$ & 2h32' & $"$ & 186 & -12 & 84 & -21 & 36 & -114 & 33.7 \\
\hline $1: 40$ & $2+52$ & $"$ & 186 & -12 & 84 & -21 & 86 & -114 & $83.6^{\circ}$ \\
\hline $2: 0$ & $3^{4} 12{ }^{\prime}$ & $"$ & 192 & -6 & 84 & -21 & 36 & -114 & 83.5 \\
\hline
\end{tabular}

The heart rate was also found accelerated with its peak at a few minutes after blecling; the greatest surplus was 12 to 24 beats per minute. The surplus in the rate lasted about a half to one hour; only in Cat 2 it was of far shorter duration. In Cat 5 the increase in the heart rate occurred soon after blceding, but after some recovery had taken place the rate was again accelerated, the second acme being reached about one hour after bleeding. In the later stadium the heart rate became smaller than the rate before bleeding. 12 to 18 beats per minute were the usual amount of reduction, only in Cat 1 it was remarkable, that is 48 a minute.

The acceleration of 12 beats per minute was not infrequently observed by Stewart and $R \circ g \circ f^{25)}$ and $C a n n o n$ and $R a p p o r{ }^{25)}$ by sensory stimulation in cats after removal of the suprarenals. The cats, which reacted with only a slight accelerated heart rate in the similar experiments of $\mathrm{Cannon}_{\mathrm{n}, 3 \cdot 3)}$ were fasting for a day or two before the opera- 
Example II.

26. VII. 1927. Cat ㅇ 2.8 kilos.

9:0 2.S grms. urethane stomachically. 10:0-11:0 Denerration of the heart, etc. 11:10-11:10:10" 50 c.c. blood ( $1 / 3$ of total blood volume) were shed from carotid artery.

\begin{tabular}{|c|c|c|c|c|c|c|c|c|}
\hline \multirow[b]{2}{*}{ Time } & \multirow[b]{2}{*}{ Time after bleeding } & \multicolumn{2}{|c|}{$\begin{array}{l}\text { Ieart beat } \\
\text { (per min.) }\end{array}$} & \multicolumn{2}{|c|}{$\begin{array}{l}\text { Blood pressure } \\
\text { (mms. Hg.) }\end{array}$} & \multicolumn{2}{|c|}{$\begin{array}{l}\text { Respiration } \\
\text { (per min.) }\end{array}$} & \multirow{2}{*}{ 总 } \\
\hline & & $\stackrel{巳}{ت}$ & 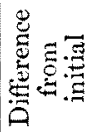 & $\begin{array}{l}\stackrel{ \pm}{\Xi} \\
\stackrel{\infty}{\Xi}\end{array}$ & 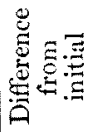 & $\stackrel{0}{0}$ & 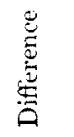 & \\
\hline 11: 0 & & 180 & & 170 & & 54 & & 86.2 \\
\hline 11: 7 & & 174 & & 150 & & & & \\
\hline $11: 10$ & Begin of bleeding & 180 & +6 & 120 & -80 & & & \\
\hline & End of bleeding & 240 & +66 & 60 & -90 & & & \\
\hline & 1 after bleeding & 246 & +72 & 70 & -80 & is & -36 & \\
\hline & $\begin{array}{lll}2^{\prime} & , & \end{array}$ & $\begin{array}{l}258 \\
250\end{array}$ & $\begin{array}{l}+84 \\
+84\end{array}$ & $\begin{array}{r}90 \\
100\end{array}$ & $\begin{array}{l}-60 \\
-50\end{array}$ & 12 & $\begin{array}{l}-42 \\
-42\end{array}$ & \\
\hline $11: 15$ & $5^{\prime} "$ & $\begin{array}{l}205 \\
252\end{array}$ & $\begin{array}{r}7+4 \\
+78\end{array}$ & 100 & -50 & $\begin{array}{l}22 \\
18\end{array}$ & $\begin{array}{l}-44 \\
-36\end{array}$ & 35.7 \\
\hline $11: 20$ & $10^{\prime} "$ & 246 & $\begin{array}{r}+72 \\
+72\end{array}$ & 70 & -80 & 18 & -36 & 85.5 \\
\hline $11: 25$ & $15^{\prime} "$ & 246 & +72 & 60 & -90 & 12 & -42 & 35.5 \\
\hline $11: 30$ & $20^{\prime} ", \quad$, & 250 & +78 & 60 & -90 & 18 & -36 & 35.2 \\
\hline $11: 35$ & Death & & & & & & & \\
\hline
\end{tabular}

tion ${ }^{25}$ The cats in the present inrestigations were fasting for two days prior to the experiment.

When one fifth of the total blood volume was lost three cats out of five died within forty minutes to two bours. In Cat 10 the blood pressure fall progressed, though slowly, till the death, but the pressure was high even at the end. Also in Cat 6 , which died about forty minutes after haernorrhage the blood pressure was high even immediately before death, as $110 \mathrm{mms}$. $\mathrm{Hg}$. The heart rate was somewhat remarkably increased throughout the experimental course. Bleeding of one fifth produced a remarkable fall in the blood pressure, the lowest level being reached as a rule some minutes after haemorrhage. Usually the initial level was not regained till the end of the experiment. In four cases out of five, the heart rate was increased ; $18-48$ beats per minute was the maximum acceleration, which was achieved some minutes after bleeding. In half of the cases the acceleration did not last so long. In Cat 8 the blood pressure underwent some intensive reduction as usual, with the minimum height at the second minute after bleeding, but the heart rate indicated no acceleration, except a slight one just at the start of haemorrhage, but set in to decrease at the end of bleeding and the diminution progressed further and further, finally a reduction of 60 beats per minute was 
discovered five hours after haemorrhage. In Cat 9 a reduction in the heart rate was also noted one hour after bleeding and betrayed a tendency to progress further; 24 beats per minute was the maximum amount of reduction. Cat 7 survived only one hour after bleeding, and till the end of the experiment there was no sign of a diminished rate.

Hacmorrhage of one third of the total blood quantity evoked an evident drop in the blood pressure, the minimum systolic pressure calculated as 25 to $70 \mathrm{mms} . \mathrm{Hg}$. a minute being reached soon after bleeding. The drop lasted the whole experimental course which was discontinued by death (4 cases) or artificially. In four out of five instances the heart bat with a more frequent rhythm, especially in thrce cases (Cats 13, 14 \& 15). 48 to 84 per minute was the maximum acceleration in the later cases, which was discovered just at the end of bleeding or 2 to 5 minutes later. (Such a great acceleration as 48 a minute was not noted in the cats deprived of the suprarenal bodies, which are given in the above quoted papers of Stew art and Rogof $f^{-3)}$ and of Cannon and Rapport..$^{-5)}$ An acceleration of 84 beats per minute was not cited there in the eases of cats with intact suprarenals.) The heart rate in these cats was found still increased before death, 12, 42 and 78 per minute being the surplus over the initial rate. In Cat 12 which well survived the blood loss, a reduction in the heart rate as 12 per minute was detected in the later stage. The result with Cat 11 somewhat differs; the heart rate increased a little at the starting of haemorrhage, but soon later the rate was reduced remarkably. A diminution of 96 a minute was recorded 5 minutes after bleeding and that of 10815 minutes, while the drop in the blood pressure was not excessive, with the degree of drop as 7 mms. $\mathrm{Hg}$. respectively 42 mms. at the corresponding periods.

To recapitulate the results above referred to: In the majority of cases the bleeding was capable of producing a rapid rate of the denervated heart, and the greater the mass bled, the greater the acceleration. The maximum acceleration took place immediately after bleeding or a few minutes later.

The body temperature underwent some reduction; when the experiment was prolonged, the drop was greater. A fall of about two degrees was the greatest. If the body temperature was successfully protected against the fall the acceleration of the denervated heart would be more extensive. This fall of tenperature may be possibly partly accounted for by the reduction of the rate of the denervated heart in the later stage.

In the cava pocket experiment of $\mathrm{Sait}{ }^{18)}$ on etherized dogs the time when the acceleration occurred in the epinephrine discharge was decidedly later than that of the maximum increase of the denervated heart rate of our uretbanized cats, say twenty to thirty minutes after bleeding. In his non-anaesthetized, non-fastened dogs the latency of the augmentation of epinephrine output was nearly similar to that in anaesthetized ones.

In the cases of severe bleeding (one third of the total blood volume), the arterial systolic 
pressure became rery low ; in Cat 12 about $50 \mathrm{mms}$. IIg., in Cat 13 about $30 \mathrm{mms}$. and in Cat $1425 \mathrm{mms}$. were the minima (The blood pressure was recorded by means of 11 ii $\mathrm{r}$ th $\mathrm{l}$ e's spring manometer). In the remaining cases (Cats $11 \& 15$ ) the minima were 70 and $60 \mathrm{mms}$. $\mathrm{Hg}$. respectively. In Cat 5 , in which one seventh of the total blood rolume was shed, and Cats 7 and 8 , in which one fifth was lost, the low pressure was also disclosed. Notwithstanding such low arterial pressure the denervated heart was found accelerated; in Cats 13 and 14 the fall of the blood pressure was conspicuous and simultaneously the acceleration of the heart rate was also remarkable. These findings seem to contradict the statement of $R a p p o r t^{30}$ in a study in traumatic shock, for example, that the denerrated heart method has such a limitation that when the blood pressure becomes low-say 50-60 mms. Ifg.the tendency of the heart rate is to drop, because the heart is being insufficiently nourished. He inferred that under such circumstances the rate of the isolated heart would be the resultant of opposite factors, increased epinephrine liberation tending to accelerate it and the decreased blood supply tending to make it slower. So, it is possible, he added, that in the later stages of shock there was, in his experiments, an increased discharge of epinephrine into the blood stream, which the method of the denerrated heart was unable to detect.

In the present researches of haemorrhage, the acceleration of denervated heart beat lasted a half to one hour in 4 cases of one-seventh-bleeding and in 1 case of one third, and it continued so long as the animal surrired, say $20-60$ minutes, in 2 cases of one fifth bleeding and 3 of one third, while it was of a very short duration in 1 case of $1 / 7$ bleeding and 2 cases of $1 / 5$.

The augmented epinephrine output in the etherized dogs prorided with the cara pocket of Saito was observel for about one hour when one fifth was bled, and it was further well establisbed in the non-anaesthetized, non-fastened dogs that the nore intensive the haemorrhage, the longer the augmentution in the epinephrine discharge la ted. By haemorrhage of one tenth the augmentation extended for 2 to 3 hours, the haemorrhage of one fifth called forth an augmentation which lasted more than 3 hours, and when one-third-bleeding was tried, a still remarkable rapid rate of dicharge was detected after the lapse of 3 or 4 hours.

Further, in the present inrestigation there are many examples in which the reduction in the denervated heart rate was not only accompanied not by low pressure, but by a fairly high one. A reduction of ts beats per minute accompanied $140 \mathrm{mms}$. $1 \mathrm{Ig}$. in $\mathrm{Cat} 1 \mathrm{(1/7}$ bleeding), 18 beats, 133 mms. in Cat $2(1 / 7), 12$ beats, 84 mms. in Cat $3(1 / 7), 12$ beats, 100 mms. in Cat $4(1 / 7)$, 18 beats, $100 \mathrm{mms}$. in Cat $5(1 / 7), 60$ beats, $105 \mathrm{mms}$. in Cit $\mathrm{S}(1 / 5), 24$ beats, $190 \mathrm{mms}$. in Cat $9(1 / 5), 12$ beats, $120 \mathrm{mms}$. in Cat $10(1 / 5)$ and 12 beats, $70 \mathrm{mms}$. in Cat $12(1 / 3)$.

So it may not be justifiable to assume an increased secretion of epinephrine in later stages after bleeding in several instances quoted in this paper notwithstanding the nonoccurrence of augmentation in the rate of denervated heart.

The present results may possibly be expressed, it may be remarked in passing, in the terms that the fall in the blood pressure is capable of causing a definite acceleration in the beat of the denervated heart and so on. It must be remembered however that a similar procedure was found to cause rather the opposite phenomenon. That is stimulation of the depressor nerve. A history of the depressor nerve on the epinephrine output or the denervated heart will be here refered to. Py stimulating the depressor Gley and Quinquaud ${ }^{31}$ failed to observe diminution of the epinephrine content of the suprarenal rein

30) Ripport, Am. J. Physiol., 1922, 60, 472.

31) E. Gley an 1 Alf. Quinquaud, C. T. Acad. Sci., 1915, 157, 66. 
blood in the rabbit. Richard and $W_{0} \mathrm{~d}^{32}$ pronounced a diminution of the epinephrine secretion by the depressor stimulation. The blood from the suprarenal gland was collected by a similar procedure as the cava pocket preparation and tested for epinephrine by means of intestine of cat. The concentration decreased on stimulation of the depressor, though not always. By irritating the depressor $\mathrm{Brücke} \mathrm{e}^{33}$ ) was able to see non-alteration of the rate of the rabbit heart, isolated from its extrinsic nervous mechanism by sectioning the ragi in the neck and removing the inferior cervical and stellate ganglia bilaterally. In the hands of Cannon and Rapportis) stimulation of the central end of the vagus or of the depressor nerve in the anaesthetized cat caused the denervated heart to beat more slowly, as much as 24 beats per minute. From the communications quoted it may then be deduced that stimulation of the depressor either induces a diminution of the rate of the denervated heart or at least does not evokes any acceleration at all, diagonally opposite action as the outcome in the present inrestigation on haemorrhage. Both the data appear as contradictory phenomena on superficial examination, but if it is taken into consideration that when the depressor nerve is set into the normal organism and how the organism must react to the bleeding, the increase of the medullisuprarenal function in the bleeding and its depression at the time when the depressor nerve is set into activity - not artificially-are both beneficial for maintenance of the blood supply in general, accordingly alco for protection of the organism. From the theoretical point of view it might be expected however that when very low pressure is induced by artificial stimulation of the depressor the former itself comes to act upon the central mechanism of epinephrine secretion in its proper sense.

The respiration became at first rery fast, the maximum being noted as a rule at a few minutes after bleeding. This nearly coincides in time with that of the blood pressure fall and the heart acceleration, a very little later or earlier. Towards the end of the experiment the breathing became slower and slower, 12 being the smallest rate per minute. In some cases a slow rhythm was noted in breathing during haemorrhage and a few minutes thereafter, that is prior to the rapid breathing. In three cases of severe haemorrhage no acceleration was seen in respiration; it was only rendered slow. With Cats $6,7 \& 8$ no attention was paid to respiration.

\section{Summary:}

In the urethanized, fasting (for two days) cats, whose vagi were cut in the neck and the inferior and stellate ganglia removed bilaterally, one seventh, one fifth or one third of the total blood volume was bled; as a consequence an acceleration resulted in the beat rate of the denervated heart and seemingly the greater the haemorrhage, the greater also the acceleration.

These results indicate highly probably that bleeding produces in urethanized cats an increased output of epinephrine.

32) A. N. Richards and W. G. Wood, An. J. Physiol., 1915(-16), 39, 54.

33) E. Th. r. Brücke, Ztschr. f. Biol., 1917, 67, 507.

34) W. B. Cannon and D. Rapport, Am. J. Physiol, 1922, 58, 338. 